\title{
Disability-inclusive workplaces provide greater value for the hospitality industry
}

\author{
Laura Upson, Alison McIntosh and Brielle Gillovic
}

Laura Upson is a postgraduate student at AUT. She is recipient of the 2020 AUT Summer Research Award. Her current research focuses on accessible tourism and hospitality for people with disabilities.

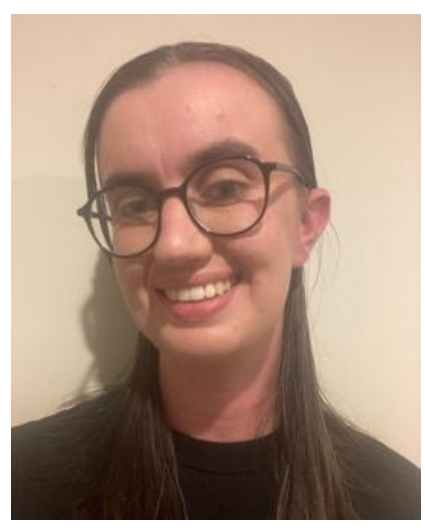

Dr Alison McIntosh is a professor of hospitality \& tourism at AUT and is a supervisor of the project.

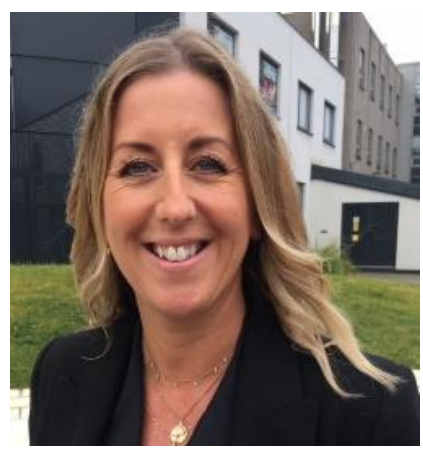

Dr Brielle Gillovic is a senior lecturer in tourism at AUT and is a cosupervisor of the project.
Scholars believe that people with disabilities are a largely untapped and underutilised hospitality-industry employment pool. In 2020, it was estimated that only $22.5 \%$ of people with disabilities were in full-time employment, in comparison to $69.3 \%$ of people without disabilities [1]. With approximately one in four New Zealanders identifying as living with disability, there is an opportunity for New Zealand's hospitality industry to realise great value from having disability-inclusive workplaces.

Our study aimed to identify the benefits of, and barriers to, employing people with disabilities in the hospitality industry. The research was carried out by undertaking a systematic literature review, which can identify, evaluate and integrate an existing body of relevant scholarly literature [2]. In order to search for literature as widely as possible, keywords relevant to the study were entered into two internet browsers: Mozilla Firefox and Google Chrome. Keywords were then entered into Google Scholar and the Scopus database in order to filter for specific tourism and hospitality journals. In total, our search found 173 journal articles relevant to the topic.

The retrieved literature revealed a number of benefits related to the inclusive employment of people with disabilities in the hospitality industry. People with disabilities were found to be loyal employees; it has been shown that they are committed to their employing organisation, minimising their likelihood of leaving, and thus reducing the rate of staff turnover. People with disabilities were also found to be engaged employees; it has been shown that employing people with disabilities increases the level of productivity, efficiency and creativity within the workplace. Lower rates of absenteeism were recorded in comparison to employees without disabilities, as well as higher levels of customer satisfaction and a greater sense of corporate social responsibility.

Inclusive employment can highlight an organisation's dedication to social inclusion and be a key differentiation strategy that is highly regarded by internal and external stakeholders, thus promoting a positive organisational image and reputation. These benefits are achievable given there are few entry barriers to hospitality industry roles that do not require much previous work experience - for example, kitchenhand or housekeeping. Additionally, the nature of the tasks within the hospitality industry are considered more routine and repetitive. 


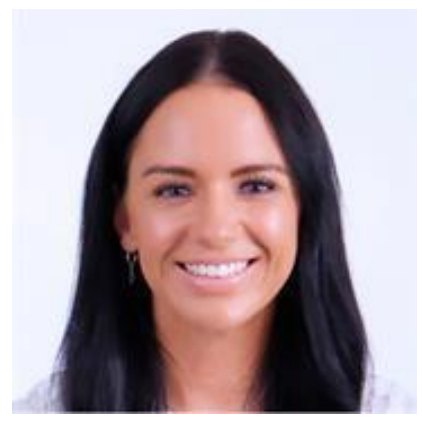

A number of challenges and barriers to the employment of people with disabilities were found, mostly related to prejudice and discrimination by human resource managers, general management and existing employees. Documented concerns were related to the perceived skills and abilities of the potential employee with a disability, and whether they had the required knowledge for the role or the industry. Additionally, others in the organisation often (mis)perceived that people with disabilities are costly to accommodate. In fact, the opposite has been found to be true. The literature also revealed limited, or lack of, access to further training or education for human resource managers around how they could better support employees with disabilities.

To conclude, our research has revealed a broad and increasing body of scholarship on the employment of people with disabilities, identifying recommendations for the hospitality industry. Of particular note is the social value for hospitality employers of employing people with disabilities; there is a need to look beyond the disability at hand, and to instead view the individual's abilities and skills, and the positive characteristics that they could bring as a potential employee. The social value of employing people with disabilities includes an increased sense of acceptance, belonging and diversity within the workplace. It was also highlighted that any initial accrued costs from accommodations needed to support the ongoing performance of employees with disabilities would also likely benefit customers with disabilities and future employees with disabilities in the longer term. Moreover, relevant national and international legislation, such as the United Nations Convention of the Rights of People with Disabilities (2006), Human Rights Act (1993), and the Bill of Rights (1990), provides a comprehensive framework that outlines the standard of accessibility and inclusivity that hospitality organisations should aim for, both now and in the future.

This research project was funded by an AUT Summer Research Award, 2020.

\section{Corresponding author}

Laura Upson can be contacted at: $\underline{\text { fm0040@autuni.ac.nz }}$

\section{References}

(1) Statistics New Zealand. Key Provisional Estimates, 2019.

https://www.stats.govt.nz/information-releases/tourism-satellite-account-2019 (accessed Nov 1, 2021)

(2) Okoli, C.; Schabram, K. A Guide to Conducting a Systematic Literature Review of Information Systems Research. Sprouts: Working Papers on Information Systems 2010, 10 (26), 1-51. 